www.jmscr.igmpublication.org

Impact Factor 5.244

Index Copernicus Value: 83.27

ISSN (e)-2347-176x ISSN (p) 2455-0450

crossref DOI: _https://dx.doi.org/10.18535/jmscr/v4i10.39

\author{
Journal Of Medical Science And Clinical Research \\ IGM Publication \\ An Official Publication of IGM Publication
}

\title{
Prevalence of Anaemia in Adolescent Girls of Khammam District
}

\author{
Authors \\ Suguna. $V^{1}$, Nymisha. $M^{2}$ \\ ${ }^{1}$ Associate Professor, Department of Obstetrics and Gynaecology, Mamata Medical College, Khammam, \\ Telangana-507001 \\ ${ }^{2}$ Assistant Professor, Department of Obstetrics and Gynaecology, Mamata Medical College, Khammam, \\ Telangana-507001 \\ Corresponding Author \\ Suguna.V \\ Associate Professor, Department of Obstetrics and Gynaecology, Mamata Medical College, Khammam, \\ Telangana-507001, Mobile No: 8019317889 \\ Email:vsugunammckmm@gmail.com
}

\begin{abstract}
Anaemia is one of the major challenges India is still facing. During adolescence, the nutrition and health needs are more because of the growth spurt and increase in physical activity. The study was conducted to find out the prevalence of anaemia among adolescent girls in and around Mamata General Hospital, Khammam. A total of 300 adolescent girls were included in the study after obtaining permission from hospital ethics committee and informed written consent was taken from girls. All were unmarried and non-pregnant adolescent girls of 10-19 years age was included. The parameter like age, height, weight, body mass index and haemoglobin levels of all participants were measured. Average haemoglobin level in this study was $11.62 \pm 2.85 \mathrm{gm} \%$. The number of adolescent girls having mild anaemia (Hb level between 10 to $11.9 \mathrm{gm} \%$ ) were244(81.3\%), whereas 39(13\%) were having moderate anaemia (Hb level between 7 to $9.9 \mathrm{gm} \%$ ), Girls with severe anaemia were 4(1.33\%) in number. However 13(4.33\%) adolescent girls had no anaemia. Most of the girls were found to have a mild degree of anaemia (81.3\%), there is a great scope for early intervention to bring the haemoglobin level in the normal range by the dietary supplements of micronutrients.
\end{abstract}

Keywords- Anaemia, Adolescent, Girls, Prevalence.

\section{INTRODUCTION}

Anaemia is common throughout the world, the highest occurrences in developing countries especially in women as they constitute the most vulnerable group particularly in those countries, where they are exposed to greater risk of reproductive morbidity and mortality. Among adults, anaemia disproportionately affects women of child bearing age. Overall, anaemia affects nearly $45 \%$ of women from developing countries and $13 \%$ of women from developed regions ${ }^{[1]}$. Anaemia has been reported through several studies to be a major micronutrient deficiency among adolescent girls across the country. The prevalence of anaemia was reported to be above 80 per cent in some states of India ${ }^{[2]}$. According to WHO estimates, India is one of the countries in the world that has highest prevalence of anaemia. In India National Family Health Survey -II (1998) shows that 54\% women in rural and $46 \%$ women in urban areas are anaemic ${ }^{[3]}$. 
Anaemia is defined as a haemoglobin concentration or haematocrit lower than the reference cut off value, traditionally less than the fifty percentile of the distribution of haemoglobin concentration in a reference population of healthy individuals of the same gender and age. Anaemia may be caused by decreased production of normal red blood cells (RBCs) and haemoglobin, increased destruction of RBC (haemolysis) or excessive blood loss. According to $\mathrm{WHO}^{[4]}$ anaemia is defined as haemoglobin less than $11 \mathrm{gm} / \mathrm{dl}$ and a haematocrit of less than 0.33. Anaemia is classified in to three categories according to severity i.e. mild ( $\mathrm{Hb}$ level between $10 \mathrm{~g} / \mathrm{dl}$ to $11 \mathrm{~g} / \mathrm{dl}$ ), moderate ( $\mathrm{Hb}$ level $7.9 \mathrm{~g} / \mathrm{dl}$ to $9.9 \mathrm{~g} / \mathrm{dl})$ and severe $(<7.8 \mathrm{~g} / \mathrm{dl})$.

Adolescence has been defined by World Health Organization as the period of life spanning the ages between 10 to 19 years ${ }^{[5]}$. Adolescents represent $22.8 \%$ of population of India ${ }^{[6]}$. Amongst adolescents, girls are doubly vulnerable, have lower priority, relatively neglected in familyand should be given more attention as they are future mothers.

The adequacy of dietary intake is important for good nutritional status of adolescent girls, as it has importance in terms of physical work.Also as they are the future mothers, inadequate dietary intake has important implications with regard to low birth weight, anaemia and adverse reproductive outcomes. Non-anaemic girls had higher scores in cognitive skills tests than the anaemic girls ${ }^{[7]}$. Even Mild Anaemia is a risk factor for loss of physical function.

NFHS-3, has reported prevalence of anaemia in the 15 to 19 year age group to be as follows, mild anaemia $(10-11.9)=39.1 \%$, moderate anaemia (7$9.9)=14.9 \%$, severe anaemia $(<7)=1.7 \%$ and any anaemia $(<12)=55.8 \%{ }^{[8]}$.

Adolescence is a significant period of human growth and maturation, unique changes occur during this period and many adult patterns are established. The proximity of adolescence to biological maturity and adulthood may provide final opportunity to implement certain activities designed to prevent adult health problems ${ }^{[6]}$.

\section{MATERIALS AND METHODS}

The study was conducted at Mamata general hospital, Khammam. The adolescent girls visiting the hospital for different purpose were included in the study after obtaining permission from hospital ethics committee. Prior to data collection each patient was informed about the purpose of the study and consent to participate in the study was taken. Cynmet method of $\mathrm{Hb}$ estimation was used. The required information was collected on a pretested semi-structured scheduled.The analysis of the data was carried out by using SPSS 16 software. All concerned and involved subjects in the study were informed of their blood test report and motivated to maintain or improve $\mathrm{Hb}$ level. The definition of adolescent girls given by the World Health Organisation (WHO) was followed as the operational definition in the present study i.e. girls between the age group 10-19 years. Early adolescence was taken as adolescent girls in the age group 10-14 years, and late adolescence 15-19 years. Anaemia was defined as having haemoglobin concentration $<12 \mathrm{gm} / \mathrm{dl}$. Severity of anaemia was graded as mild $(10-12 \mathrm{~g} / \mathrm{dl})$, moderate $(7-10 \mathrm{~g} / \mathrm{dl})$ and severe $(<7 \mathrm{~g} / \mathrm{dl})$.

\section{RESULTS}

The study was conducted at gynaecology department of Mamatha general hospital. A total of 300 girls were enrolled in this study. The adolescent girls of aged from 10-19year were taken in to study. The demographic data of age, height, weight and body mass index was given in table 1 .Among the 300 adolescent girls, $150(50 \%)$ belonged to early adolescence (10-14 years) and $150(50 \%)$ to late adolescence (15-19 years) age group. Distribution of Adolescent girls according to religion showed that the majority of them were Hindus150 (50\%), 69(23\%)were Muslims and 81(27\%) were Christians. Majority of Adolescent girls270 (90\%) belonged to nuclear family. The $32 \%$ adolescent girls were involved in household work, $68 \%$ were students. The mean height of adolescent girls was found to increase as age increases however maximum difference was seen between 12 and 13 years is due to growth spurt. As a whole $44.2 \%$ of 
adolescent girls were found 'Underweight' based on weight for ageless than 5th percentile of NCHS standard, prevalence of underweight was higher at 18 years.

Table 1:-Age wise Height, Weight and BMI of adolescent girls

\begin{tabular}{|l|l|l|l|l|}
\hline $\begin{array}{l}\text { Age } \\
\text { (years) }\end{array}$ & No & $\begin{array}{l}\text { Height }(\mathbf{c m s}) \\
(\text { Mean } \pm \text { s.d) }\end{array}$ & $\begin{array}{l}\text { Weight(kg) } \\
(\text { Mean } \pm \text { s.d) }\end{array}$ & $\begin{array}{l}\text { BMI(Kg/m2) } \\
(\text { Mean } \pm \text { s.d) }\end{array}$ \\
\hline 10 & 30 & $133.6 \pm 1.45$ & $25.84 \pm 2.16$ & $14.05 \pm 1.36$ \\
\hline 11 & 30 & $137.2 \pm 3.29$ & $27.40 \pm 4.23$ & $15.46 \pm 1.23$ \\
\hline 12 & 30 & $141.5 \pm 5.29$ & $31.26 \pm 5.63$ & $16.25 \pm 2.02$ \\
\hline 13 & 30 & $146.2 \pm 6.45$ & $37.25 \pm 6.42$ & $16.98 \pm 2.75$ \\
\hline 14 & 30 & $151.2 \pm 2.36$ & $42.37 \pm 6.45$ & $18.52 \pm 2.85$ \\
\hline 15 & 30 & $151.6 \pm 5.32$ & $42.53 \pm 3.25$ & $18.62 \pm 2.65$ \\
\hline 16 & 30 & $152.2 \pm 6.32$ & $43.25 \pm 3.25$ & $18.52 \pm 2.87$ \\
\hline 17 & 30 & $153.2 \pm 2.35$ & $44.23 \pm 4.29$ & $18.23 \pm 2.36$ \\
\hline 18 & 30 & $154.6 \pm 4.25$ & $43.25 \pm 5.21$ & $18.20 \pm 2.44$ \\
\hline 19 & 30 & $154.8 \pm 4.32$ & $44.80 \pm 6.23$ & $18.42 \pm 2.31$ \\
\hline
\end{tabular}

Average haemoglobin level in this study was $11.62 \pm 2.85 \mathrm{gm} \%$.The number of adolescent girls having mild anaemia ( $\mathrm{Hb}$ level between 10 to 11.9 gm\%) were244(81.3\%), whereas 39(13\%) were having moderate anaemia ( $\mathrm{Hb}$ level between 7 to $9.9 \mathrm{gm} \%)$ and Girls with severe anaemia were 4 $(1.33 \%)$ in number. However $13(4.33 \%)$ adolescent girls had no anaemia. The age wise distribution of haemoglobin was shown in table 2 . The proportion of non-menstruating girls in the present study was $44.8 \%$ and menstruating were $53.2 \%$.In the present study the prevalence of anaemia was $95.66 \%$, as per WHO criteria i.e. prevalence $>40 \%$, the magnitude of anaemia problem was high. But as per severity, it was a low magnitude problem. Anaemia showed positive correlation with age and it increased significantly with age.

Table 2: Age wise distribution of Haemoglobin levels among adolescent girls

\begin{tabular}{|l|l|l|l|l|l|}
\hline $\begin{array}{l}\text { Age } \\
\text { Years) }\end{array}$ & \multicolumn{6}{|l|}{$\begin{array}{l}\text { No of persons showing Haemoglobin levels } \\
\text { (gm \%) }\end{array}$} & $<7.0$ & $7.0-9.9$ & $10-11.9$ & 12 or $>$ & Total \\
\hline & 0 & 0 & 27 & 3 & 30 \\
\hline 10 & 0 & 0 & 27 & 3 & 30 \\
\hline 11 & 0 & 0 & 28 & 2 & 30 \\
\hline 12 & 0 & 5 & 24 & 1 & 30 \\
\hline 13 & 0 & 5 & 24 & 1 & 30 \\
\hline 14 & 0 & 5 & 24 & 1 & 30 \\
\hline 15 & 1 & 6 & 22 & 1 & 30 \\
\hline 16 & 1 & 7 & 21 & 1 & 30 \\
\hline 17 & 1 & 6 & 23 & 0 & 30 \\
\hline 18 & 1 & 5 & 24 & 0 & 30 \\
\hline 19 & &
\end{tabular}

\section{DISCUSSION}

Adolescence is characterized by series of biochemical, anatomical and mental changes that are not found in members of other age groups.It is these rapid extensivechanges that differentiate adolescents from children and adults, that must be takeninto account when adolescents and their health problems are being given attention ${ }^{[9]}$.During this period more than $20 \%$ of total growth in stature, and upto $50 \%$ of adult bonemass is achieved. Adolescent Growth spurt results in 50\% increase in calciumrequirement and $15 \%$ increase in iron requirement ${ }^{[10]}$.

NFHS-3, has reported prevalence of anaemia in the 15 to 19 year age group to be as follows, mild anaemia $(10-11.9)=39.1 \%$, moderate anaemia (7$9.9)=14.9 \%$, severe anaemia $(<7)=1.7 \%$ and any anaemia $(<12)=55.8 \%$. A variable prevalence (23.9\% to $96.5 \%$ ) of anaemia in adolescent girls has been reported in various studies conducted earlier in India. The prevalence reports of different studies were differing according to the socioecomic status of that area. Anand et al ${ }^{[11]}$ has reported the prevalence of anaemia was $51 \%$ in young $\operatorname{girls}(n=39)$ compared to $38.5 \%(n=39)$ in older girls. Sen et al ${ }^{[12]}$ observed that $32.6 \%$ girls to be mildly anaemic, $34.7 \%$ girls moderately anaemic and no severely anemic girls. Verma et al ${ }^{[13]}$ have observed that the overall prevalence of mild, moderate and severe anaemia have been $55.2 \%, 26 \%$, and $0.6 \%$ respectively. Jolly et al ${ }^{[14]}$ observed the prevalence of anaemia has been $44.8 \%$ with severe anaemia being2.1\%, moderate $6.3 \%$ and mild anaemia $36.5 \%$. The prevalence of anaemia has been $40.7 \%$ inpre-menarcheal girls as compared to $45.2 \%$ in post menarcheal girls. Singh et al ${ }^{[15]}$ has reported that the mean Haemoglobin was 10 gm $\%, 56 \%$ girls have been anaemic of which $10.5 \%$ have moderate anaemia while $45.5 \%$ have been mildly anaemic. Ramachandran et al ${ }^{[16]}$ reported prevalence of anaemia was $73.5 \%$, mild, moderate and severe anaemia being present in $77.3 \%, 20.2 \%$ and $2.5 \%$ of the participants respectively.

In the present study prevalence of anaemia was $95.66 \%$ with mild, moderate and severe anaemia were $81.3 \%, 13 \%$ and $1.3 \%$ respectively. A very 
high proportion of anaemia has been noted in the present study. Population covered under General hospital were belongs to low socio economic status. Most of girls were having mild anaemia which can be taken care by improving the dietary supplements. Anaemia showed positive correlation with age and it increased significantly with age and similar observations were made by others ${ }^{[17]}$.

\section{CONCLUSIONS}

Most of the girls were found to have a mild degree of anaemia (81.3\%), there is a great scope for early intervention to bring the haemoglobin level in the normal range by dietary supplements. Even today, girls are considered as unnecessary expense. Adolescent girl is the future mother and adolescence offers us the second and last opportunity to improve her nutritional status. More attention needs to be directed towards this age group to have healthy nation in future.

\section{ACKNOWLEDGEMENT}

Authors acknowledge the immense help received from Mamata medical college, the scholars whose articles are cited and included in references of this manuscript.

\section{REFERENCES}

1. El-Sahn F, Sallam S, A. Mandil and Galal O. Anaemia among Egyptian adolescents: prevalence and determinants. Eastern Mediterranean Health Jour. 2000;6 (6/5):1017-25.

2. Studies on Adolescent Girls-An Analytical Review by NIPCCD. Micronutrient Malnutrition-Anemia. Available from: http://nipccd.nic.in/reports/eag.pdf

3. Nisar N, White F. Factors affecting utilization of antenatal care among reproductive age group women (15-49 years) in an urban squatter settlement of Karachi. J. Pak Med Assoc 2003; 53: 47-53.

4. Nutritional Anemia. Report of WHO Scientific Group 1968. World Health Organ Tech Rep Ser 1968; 405:5-37.
5. The reproductive health of adolescents :A strategy for action.W.H.O.(1989)A joint W.H.O./U.N.F.P.A./U.N.I.C.E.F.statement.

6. Ghai O.P.:- Essential paediatrics, 6th edition CBS publishers.2004

7. Breymann C. Iron deficiency and anemia in pregnancy: Modern aspects of diagnosis and therapy. Blood CellsMolDis 2002;29:506-16

8. National Family Health Survey(NFHS-3), 2005-06; International Institute of Population Sciences, Mumbai,India.

9. Health problems of adolescence, report of a W.H.O. expert committee. W.H.O.(1965) Technical Report Series No.308.

10. SathyavathiK.and Agarwal K.N.: Adolescent Growth Studies- Part A.Physiological aspects and environmental factors. Indian Paediatrics 1979;16(2);197-205.

11. AnandK.,KantS.,Kapoor S.K.:-Nutritional status of adolescent school children in rural North India. In.Paed, Aug.1999; 36,810-815

12. A.Sen,S.J.Kanani:-Mental capacity in young adolescents. Indian Paediatrics.2006;43

13. A.Verma,V.S.Rawat,G.Kedia,D.Kumar,J.Ch auhan. Factors influencing anemia among girls of school going age(6-18) from slums of Ahmedabad city. Indian journal of Comm Medicine, Jan-March 2004, Vol 29,No1

14. Jolly R.,AsokanJ.S.,Jonathan Paul et al:Prevalence of anaemia amongadolescent girls of rural Tamilnadu. Indian Paediatrics, May 2000; vol.37;532- 535.

15. Singh J, Singh J.V,Shrivastava A.K., Suryakant :-Health status of adolescent girls inslums of Lucknow, Indian Jou. of comm Medicine April-June 2006;. 31(2)102-103.

16. Ramachandran R, Majumdar A, Kar Prevalence and risk factors of Anaemia among adolescent girls residing in a rural community of Puducherry. Indian Journal Of Maternal And Child Health, 2013;15(4):1-8.

17. Bharti P, Shome S, Chakrabarty S, Bharti S, $\mathrm{Pal}$ M. Burden of anemia and its socioeconomic determinants among adolesc-ent girls in India. Food Nutr Bull 2009Sept; 30 (3):217-26. 